\title{
Theoretical Models to Predict the Mechanical Behavior of Thick Composite Tubes
}

\author{
Volnei Tita $^{\mathrm{a}, *}$, Mauricio Francisco Caliri Júnior ${ }^{\mathrm{a}}$, Ernesto Massaroppi Junior ${ }^{\mathrm{b}}$ \\ a Department of Aeronautical Engineering, Engineering School of São Carlos, \\ University of São Paulo - USP, Av. Trabalhador São-Carlense 400, São Carlos, SP, Brazil \\ ${ }^{\mathrm{b}}$ Department of Mechanical Engineering, Engineering School of São Carlos, \\ University of São Paulo - USP, Av. Trabalhador São-Carlense 400, São Carlos, SP, Brazil
}

Received: June 8, 2011; Revised: September 5, 2011

\begin{abstract}
This paper shows theoretical models (analytical formulations) to predict the mechanical behavior of thick composite tubes and how some parameters can influence this behavior. Thus, firstly, it was developed the analytical formulations for a pressurized tube made of composite material with a single thick ply and only one lamination angle. For this case, the stress distribution and the displacement fields are investigated as function of different lamination angles and reinforcement volume fractions. The results obtained by the theoretical model are physic consistent and coherent with the literature information. After that, the previous formulations are extended in order to predict the mechanical behavior of a thick laminated tube. Both analytical formulations are implemented as a computational tool via Matlab code. The results obtained by the computational tool are compared to the finite element analyses, and the stress distribution is considered coherent. Moreover, the engineering computational tool is used to perform failure analysis, using different types of failure criteria, which identifies the damaged ply and the mode of failure.
\end{abstract}

Keywords: composite material, thick tubes, analytical formulation, stress analyses, failure analysis

\section{Introduction}

Composite materials have been more and more widely applied on the production of structural components in many areas such as the petroleum and the aeronautical industries, as well as composite structural repairs for civil constructions. However, mapping the stresses and predicting the failure in a structure manufactured by composite material is a challenge due to the inherent anisotropy. Thus, composite structures such as tubes and cylinders have been studied by many researchers. Also, due to their cylindrical symmetry, it is possible to find at the literature many contributions about stress analyses for these structures, using theoretical models (e.g. analytical formulations).

Considering the structural design with anisotropic materials, Lekhnitskii ${ }^{1-2}$ is an important reference, because this author derived generic analytical formulations for the main loading cases applied on anisotropic media. In 1988, Durban ${ }^{3}$ studied finite elastic-plastic deformations on pressurized tubes. Later, in 1989, the researcher improved his work, including formulations for large strains and composite materials ${ }^{4}$. A rather feasible and specific formulation was shown by Wüthrich ${ }^{5}$, who studied a laminate thick-walled under a specific set of loading cases. In 1995, Sayir and Motavalli ${ }^{6}$ analyzed a composite laminate tube, describing the limitations of the Classical Laminate Theory (CLT) for cylindrical geometries. They decided to propose an alternative and more accuracy solution for this problem. In the same year, Salzar ${ }^{7}$ published a

*e-mail: voltita@sc.usp.br study about the stress distribution at tubes with different reinforcement volume fractions, aiming to obtain lighter and more efficient structures. A theoretical model for tubes under several loading cases such as torsion, flexion and pressurization was presented by Tarn and Wang ${ }^{8}$. These researchers and many others based on the deductions for anisotropic structures developed by Lekhnitskii ${ }^{2}$. Due to the unlimited possible setups for composite tubes, this area continues to attract researchers like Gning et al. ${ }^{9}$ (2005) and Onder et al. ${ }^{10}$ (2009), who recently studied the failure of composite tubes either by impact or burst, respectively. Still in 2009, Silvestre ${ }^{11}$ studied non-classical effects of composite tubes, investigating failure by instabilities via a proposed General Beam Theory (GBT). Besides, the researcher compared the GBT results to numerical analysis carried out by a finite element program, Abaqus ${ }^{\mathrm{TM}}$. Anasari, Alisafaei and Ghadi ${ }^{12}$, as well as Bakaiyan, Hosseini and Ameri ${ }^{13}$ analyzed multi-layered filament wound tubes under internal pressure and thermomechanical effects. In 2010, Alexander and Ochoa ${ }^{14}$ showed the feasibilities of using carbon fiber reinforced composites as composite structural repair for steel risers offshore, where the main loading was internal pressure. And lately (in 2011), Shadmehri, Derisi and $\mathrm{Hoa}^{15}$ showed analytical formulations to determine the stiffness of composite tubes. Also, the recent work of Piekarczyk et al. ${ }^{16}$ showed that even single or double layer laminates are currently in use. The researchers investigated laminates as structural repair for concrete cylinders. There 
was registered a considerable increase in the axial strength up to three times the original value.

In this context, this paper shows theoretical models (analytical formulations) to predict the mechanical behavior of thick composite tubes and how some parameters (e.g. reinforcement volume fraction) can influence this behavior. Thus, firstly, it was developed the analytical formulations for a pressurized tube made of composite material with a single thick ply and only one lamination angle. For this case, the stress distribution and the displacement fields are investigated as function of different lamination angles and reinforcement volume fractions. Also, the ply properties are estimated by a micromechanical analysis. After that, the previous formulations are extended in order to predict the mechanical behavior of a thick laminated tube, considering similar boundaries and loading applied earlier. It is important to mention that an engineering computational tool was developed, because the analytical formulations were implemented via Matlab code. Based on this computational tool, stress analyses were carried out and the results were compared to the finite element model results. Finally, the final goal of this work, in fact, consists on predicting the failure of the laminated tube using the computational tool. Therefore, three common failure models were implemented, as well as a new failure model proposed by Tita et al. ${ }^{17}$, which was never used to predict failure mechanisms for composite tubes.

\section{Composite Tube with a Single Lamination Direction}

The first analytical formulations were developed for a thick tube under internal and external pressure (Figure 1a) and manufactured by composite material with anisotropic properties in global cylindrical coordinates (Figure 1b). All interfaces were assumed perfect and tube's wall consists of a thick layer (also named "a set", which is the stacking of several thin plies to achieve the thickness specified by the project) with fibers aligned in a lamination angle $\phi$ different of zero, shown by Figure 1b, 1c.

\subsection{Theoretical formulation - part 1}

Based on Figure 1, a simplification is used in the theoretical formulation due to the applied loading and geometry of the tube. A 2D approach is used for a section of the tube. Then, the formulation is extended and the third dimension is added, composing a cylindrical coordinate system $(r-\theta-z)$. Regarding lamination angle different than 0 and $90^{\circ}$, there are shearing-stretching-coupling effects. However, in this formulation, the shear stresses and strains at planes $r-\theta$ and $z-\theta$ are taken to be relatively small compared to others, hence, one assumes:

$\varepsilon_{r \theta}=\varepsilon_{z \theta}=\tau_{r \theta}=\tau_{z \theta}=0$

In this case, the $\mathrm{z}$ direction loading can be further treated separately. To solve the problem, it is necessary to consider only the loadings in $r$ and $\theta$ directions, whose equilibrium equations produce:

$\frac{\partial \sigma_{r}}{\partial r}+\left(\sigma_{r}-\sigma_{\theta}\right) \frac{1}{r}=0$

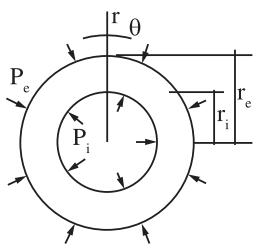

(a)

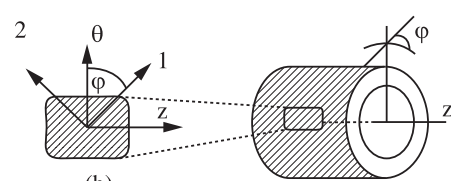

(c)
Figure 1. Thick composite tube: a) section of the tube with internal and external pressure; b) system of coordinates: cylindrical and material coordinates; c) lamination angle $\phi$.

Considering only radial displacements:

$\varepsilon_{r}=\frac{d u}{d r} ; \varepsilon_{\theta}=\frac{u}{r} ; \varepsilon_{z}=\varepsilon_{0}=$ constant

The composite tube has a lamination angle $\phi$ measured counterclockwise from the direction $\theta$ of the cylinder. Therefore, initially, the tube has one plane of symmetry, which is perpendicular to direction $\mathrm{z}$. The constitutive matrix in a global coordinate system $(r-\theta-z)$ depends on the lamination angle $\phi$ and the coefficients of the constitutive matrix defined in a local coordinate system (1-2-3) $\mathrm{C}_{\mathrm{ij}}{ }^{*}$. These coefficients are calculated as function of mechanical properties for each constituent material (fibers and matrix) as written by Mendonça ${ }^{18}$ and Christensen ${ }^{19}$. Hence the stress-strain relation in a global coordinate system $(r-\theta-z)$ is given by:

$$
\left\{\begin{array}{c}
\sigma_{\theta} \\
\sigma_{r} \\
\sigma_{z} \\
\tau_{r z}
\end{array}\right\}=\left[\begin{array}{cccc}
C_{11} & C_{12} & C_{13} & 0 \\
C_{12} & C_{22} & C_{23} & 0 \\
C_{13} & C_{23} & C_{33} & 0 \\
0 & 0 & 0 & C_{66}
\end{array}\right]\left\{\begin{array}{c}
\varepsilon_{\theta} \\
\varepsilon_{r} \\
\varepsilon_{z} \\
\gamma_{r z}
\end{array}\right\}
$$

With Equation 3 and 4 applied on the equilibrium Equation 2, it is possible to write the following nonhomogeneous second order differential, Equation 5. Considering that each layer is transversally isotropic $\left(\mathrm{C}_{22}=\mathrm{C}_{33}\right.$ and $\left.\mathrm{C}_{12}=\mathrm{C}_{13}\right)$ and the ratio $\mathrm{C}_{12} / \mathrm{C}_{22}<1$, as well as the ratio $\mathrm{C}_{11} / \mathrm{C}_{33}>1$.

$$
\frac{d^{2} u}{d r^{2}}+\frac{1}{r} \frac{d u}{d r}-\frac{1}{r^{2}}\left(\frac{C_{11}}{C_{33}}\right) u=\left(\frac{C_{12}-C_{23}}{C_{33}}\right) r \varepsilon_{0}
$$

Equation 5 has a homogeneous solution: $\mathrm{u}=\mathrm{cr} \eta$. Where $\mathrm{c}$ is a constant and $\eta$ is a parameter to be defined. The homogeneous solution plus a particular one is written at Equation 6 and it can be found at Wüthrich ${ }^{5}$.

$$
\begin{aligned}
& u(r)=c_{1} r^{\eta}+c_{2} r^{-\eta}+c_{3} r \rightarrow \text { for }: \eta=\left(C_{11} / C_{33}\right)^{1 / 2} ; \\
& c_{3}=\varepsilon_{0}\left(C_{12}-C_{23}\right) /\left(C_{33}-C_{11}\right)
\end{aligned}
$$

The solution presented is re-written for very long cylinder, where these ends have their displacements towards direction $\mathrm{z}$ set to a null value. A similar case to a section of an infinite tube; where the strains $\varepsilon_{\mathrm{zr}}$ and $\varepsilon_{\mathrm{z}}$ are also considered null. Using the mentioned constitutive relations and considering the hypothesis for the strains, the stress 
distribution in the composite tube are obtained as functions of the radial coordinate $\mathrm{r}$ :

$$
\begin{aligned}
& \sigma_{r}(r)=c_{1}\left(C_{13}+\eta C_{33}\right) r^{\eta-1}+c_{2}\left(C_{13}-\eta C_{33}\right) r^{-(\eta+1)} \\
& \sigma_{z}(r)=c_{1}\left(C_{12}+\eta C_{23}\right) r^{\eta-1}+c_{2}\left(C_{12}-\eta C_{23}\right) r^{-(\eta+1)} \\
& \sigma_{\theta}(r)=c_{1}\left(C_{11}+\eta C_{13}\right) r^{\eta-1}+c_{2}\left(C_{11}-\eta C_{13}\right) r^{-(\eta+1)}
\end{aligned}
$$

Applying the boundary conditions $\left(\sigma_{r}\left(r_{i}\right)=-P_{i}\right.$ and $\left.\sigma_{\mathrm{r}}\left(\mathrm{r}_{\mathrm{e}}\right)=-\mathrm{P}_{\mathrm{e}}\right)$, radial, hoop and axial stresses, as well as the radial displacement are calculated by the following equations:

$$
\begin{aligned}
& \sigma_{r}(r)=\left[\frac{P_{e}\left(r_{i} / r_{e}\right)^{-(1+\eta)}-P_{i}}{r_{i}^{\eta-1}-r_{e}^{2 \eta} r_{i}^{-(1+\eta)}}\right] r^{\eta-1} \\
& -\left[\frac{P_{e}}{r_{e}^{-(1+\eta)}}+\frac{\left(P_{e}\left(r_{i} / r_{e}\right)^{-(1+\eta)}-P_{i}\right)}{\left(r_{i}^{\eta-1} / r_{e}^{2 \eta}\right)-r_{i}^{-(\eta+1)}}\right] r^{-(\eta+1)} \\
& \sigma_{\theta}(r)=\left[\frac{P_{e}\left(r_{i} / r_{e}\right)^{-(1+\eta)}-P_{i}}{r_{i}^{\eta-1}-r_{e}^{2 \eta} r_{i}^{-(1+\eta)}}\right] \frac{\left(C_{11}+\eta C_{13}\right)}{\left(C_{13}+\eta C_{33}\right)} r^{\eta-1} \\
& -\left[\frac{P_{e}}{r_{e}^{-(1+\eta)}}+\frac{\left(P_{e}\left(r_{i} / r_{e}\right)^{-(1+\eta)}-P_{i}\right)}{\left(r_{i}^{\eta-1} / r_{e}^{2 \eta}\right)-r_{i}^{-(\eta+1)}}\right] \frac{\left(C_{11}-\eta C_{13}\right)}{\left(C_{13}-\eta C_{33}\right)} r^{-(\eta+1)} \\
& \sigma_{z}(r)=\left[\frac{P_{e}\left(r_{i} / r_{e}\right)^{-(1+\eta)}-P_{i}}{r_{i}^{\eta-1}-r_{e}^{2 \eta} r_{i}^{-(1+\eta)}}\right] \frac{\left(C_{12}+\eta C_{23}\right)}{\left(C_{13}+\eta C_{33}\right)} r^{\eta-1} \\
& -\left[\frac{P_{e}}{r_{e}^{-(1+\eta)}}+\frac{\left(P_{e}\left(r_{i} / r_{e}\right)^{-(1+\eta)}-P_{i}\right)}{\left(r_{i}^{\eta-1} / r_{e}^{2 \eta}\right)-r_{i}^{-(\eta+1)}}\right] \frac{\left(C_{12}-\eta C_{23}\right)}{\left(C_{13}-\eta C_{33}\right)} r^{-(\eta+1)} \\
& u(r)=\frac{1}{\left(C_{13}+\eta C_{33}\right)}\left[\frac{P_{e}\left(r_{i} / r_{e}\right)^{-(1+\eta)}-P_{i}}{r_{i}^{\eta-1}-r_{e}^{2 \eta} r_{i}^{-(1+\eta)}}\right] r^{\eta} \\
& -\frac{1}{\left(C_{13}-\eta C_{33}\right)}\left[\frac{P_{e}}{r_{e}^{-(1+\eta)}}+\frac{\left(P_{e}\left(r_{i} / r_{e}\right)^{-(1+\eta)}-P_{i}\right)}{\left(r_{i}^{\eta-1} / r_{e}^{2 \eta}\right)-r_{i}^{-(\eta+1)}}\right] r^{-\eta}
\end{aligned}
$$

It is possible to write the equations for the anisotropic tube with a generic lamination angle $\phi$ different of zero, measured from direction $\theta$. For this approach, it is necessary to consider the tube (thick layer) made of orthotropic and transversally isotropic material. Thus, there is a plane of symmetry perpendicular to the directions of the fibers (Figure 1 - r-z plane). The analytical formulation requires elastic properties of the constituent materials (fibers and matrix), which are obtained by a method developed by Hashin $^{20}$, using the CCA (Composite Cylinder Assemblage). This method is similar to the Rule of Mixtures. From Equations 14 to 18, some elastic properties of the composite are defined by the following Equations 14-18:

$$
\begin{aligned}
& E_{11}=w E_{f}+(1-w) E_{m}+ \\
& \frac{4 w(1-w)\left(v_{f}-v_{m}\right)^{2}}{\left[(1-w) /\left(K_{f}+G_{f} / 3\right)\right]+\left[w /\left(K_{m}+G_{m} / 3\right)\right]+1 / G_{m}}
\end{aligned}
$$

$$
\begin{aligned}
& v_{12}=w v_{f}+(1-w) v_{m} \\
& +\frac{w(1-w)\left(v_{f}-v_{m}\right)\left[1 /\left(K_{m}+G_{m} / 3\right)-1 /\left(K_{f}+G_{f} / 3\right)\right]}{\left[(1-w) /\left(K_{f}+G_{f} / 3\right)\right]+\left[w /\left(K_{m}+G_{m} / 3\right)\right]+1 / G_{m}} \\
& G_{23}=G_{m}\left[1+\frac{w}{\frac{G_{m}}{\left(G_{f}-G_{m}\right)}+\frac{\left(K_{m}+7 G_{m} / 3\right)}{\left(2 K_{m}+8 G_{m} / 3\right)}}\right] \\
& G_{23}=G_{m} \frac{G_{f}(1+w)+G_{m}(1-w)}{G_{f}(1-w)+G_{m}(1+w)} \\
& \mu_{23}=K_{m}+\frac{G_{m}}{3} \\
& +\frac{w}{1 /\left[K_{f}-K_{m}+\left(G_{f}-G_{m}\right) / 3\right]+(1-w) /\left[K_{m}+4 G_{m} / 3\right]}
\end{aligned}
$$

Where $\mathrm{m}$ and $\mathrm{f}$ are sub indexes, which refer to the properties of the matrix and the fibers respectively; $w$ is the volume fraction of fibers in the composite. $G, E, K, \mu, \nu$ are respectively the shear modulus, Young's modulus, Bulk's modulus, plane strain Bulk's modulus and the Poisson's coefficient. Combining Equation 4 and Equations 14-18, the material parameters used by the Equation 10-13 can be obtained as follow below:

$$
\begin{gathered}
\frac{\left(C_{11} \pm \eta C_{13}\right)}{\left(C_{13} \pm \eta C_{33}\right)}=\frac{\left(\begin{array}{l}
\left(E_{11}+4 v_{12}^{2} \mu_{23}\right) t^{4} \\
+4\left(\mu_{23} v_{12}+G_{12}\right) s^{2} t^{2} \\
+\left(G_{23}+\mu_{23}\right) s^{4}
\end{array}\right) \pm \eta\left(\begin{array}{l}
2 \mu_{23} v_{12} t^{2} \\
+\left(\mu_{23}-G_{23}\right) s^{2}
\end{array}\right)}{\left(2 \mu_{23} v_{12} t^{2}+\left(\mu_{23}-G_{23}\right) s^{2}\right) \pm \eta\left(G_{23}+\mu_{23}\right)} \\
\frac{\left(\begin{array}{l}
E_{11}+4 v_{12}^{2} \mu_{23} \\
+G_{23}+\mu_{23}-4 G_{12}
\end{array}\right) s^{2} t^{2}}{\left(C_{12} \pm \eta C_{23}\right)}=\frac{+2 \mu_{23} v_{12}\left(s^{4}+t^{4}\right) \pm \eta\left(\begin{array}{l}
2 \mu_{23} v_{12} s^{2} \\
+\left(\mu_{23}-G_{23}\right) t^{2}
\end{array}\right)}{\left(2 \mu_{23} v_{12} t^{2}+\left(\mu_{23}-G_{23}\right) s^{2}\right) \pm \eta\left(G_{23}+\mu_{23}\right)}
\end{gathered}
$$

$$
\frac{1}{\left(C_{13} \pm \eta C_{33}\right)}=\frac{1}{\left(2 \mu_{23} v_{12} t^{2}+\left(\mu_{23}-G_{23}\right) s^{2}\right) \pm \eta\left(G_{23}+\mu_{23}\right)}
$$

For : $\quad \eta=\left(\frac{E_{11}+4 v_{12}^{2} \mu_{23}}{G_{23}+\mu_{23}}\right)^{1 / 2} ; s=\sin \phi ; t=\cos \phi ;$

Thus, the material parameters in Equations 10-13 written in the global coordinate system $r-\theta-z$ remain as a function of the lamination angle $\phi$ and the elastic properties, which are obtained in the local coordinate system (1-2-3).

\subsection{Results for composite tube with a single lamination direction}

The theoretical model was implemented via Matlab code as an engineering computational tool. Thus, it is possible to investigate how different materials (e.g. type of fibers) and manufacturing parameters (e.g. lamination angle) can influence on the mechanical behavior of the thick 
composite tube. It is important to mention that variation of parameters leads to modified stiffness, strength, weight and cost of the structure. In this paper, as a first approach, it was investigated the influence of the volume fraction of fibers within a feasible percentage range $(\mathrm{w}=25-75 \%)$ for a fixed lamination angle $\left(\phi=30^{\circ}\right)$. Then, it was studied the influence of the lamination angle $\left(\phi=0-90^{\circ}\right)$, keeping a fixed volume fraction of fibers $(\mathrm{w}=50 \%)$. Two different types of fibers were investigated, also. One tube was made of epoxy resin reinforced by graphite fibers and another one was made of the same epoxy resin, but reinforced by glass fibers. However, it is very important to observe that the formulation can be applied for any type of reinforcement.

For the analyses, using the computational engineering tool, some material properties must be calculated. However, due to slight differences between the chemical compositions of each constituent material, some material properties of the composite were considered as an average of values found at literature (Table 1). The tube analyzed has internal radius $r_{i}$ equal to $0.12 \mathrm{~m}$ and external one $r_{e}$ equal to $0.15 \mathrm{~m}$. The loading is internal pressure $\mathrm{P}_{\mathrm{i}}$ of $20 \mathrm{MPa}$ combined to external pressure $\mathrm{P}_{\mathrm{e}}$ of $0.1 \mathrm{MPa}$.

Figure 2 shows the variation of the stresses and the radial displacement through the thickness as a function of the volume fraction of fibers $\mathrm{w}$ and the lamination angle $\phi$ for the tube reinforced by graphite fibers. Similar graphics for tubes reinforced by glass fibers are shown by Figure 3.

The maximum and minimum values (through the thickness) obtained for all stresses and for radial displacement at the tube are shown by Figure 4 and 5 . These results show that the computational tool can aid engineers during the preliminary project of composite tubes, because a parametric study can be performed. For example, based on Figure 4a, it is possible to assert that the radial stresses $\sigma_{\mathrm{r}}$ do not vary substantially anywhere through the thickness as one varies the type of the fiber, or the volume fraction of fibers, or even, with the lamination angle, considering the analyzed tube. Figure $4 \mathrm{~b}$ shows similar behavior for glass fiber reinforcements, considering stresses in the hoop direction $\sigma \theta$, but there is a variation in the behavior for the graphite fiber reinforcements. Furthermore, hoop stresses for both types of reinforcements tend to increase at the inner surface and decrease at the outer surface of the tube (Figure 4b). Increasing the lamination angle $\phi$, the hoop stresses tend to reduce at the inner surface, because the contribution of the fibers in the total stiffness decreases. In fact, if the fibers are no longer aligned with the direction of the largest loadings, then the response of the structure depends mainly on the matrix behavior. These results can be observed clearly at the tube with graphite fibers (Figure 2b), because this structure is stiffer than the tube reinforced by glass fibers (Figure 3b). Thus, these predictions are physically consistent and very coherent with literature information.

For the axial stresses $\sigma_{z}$, in Figure 5a, it is interesting to observe that the variation of the parameters provides different maximums and minimums in each tubes reinforced by graphite fibers, concerning an increment of the reinforcement volume fraction. For the tubes reinforced by glass fibers, an increase of the reinforcement volume fraction leads to a slight decrease of the axial stresses at the inner surface and an increase at the outer surface (Figure 3c). On the other hand, the tube reinforced by graphite fibers behaves inversely, because an increase of the reinforcement volume fraction contributes to increase the axial stress at the inner surface (Figure 2c). This phenomenon occurs due to the transversal elastic properties of the fiber glass composites, which have properties values very close to the epoxy resin (Table 1). However, this phenomenon does not happen to the graphite fiber composites, which Young's modulus, in the fiber direction, is much higher than the epoxy resin. This explains the different levels of the axial stresses between the analyzed tubes.

Nevertheless, in Figure 2d and 3d, for increments of the lamination angle, it can be observed that the axial stresses increase, because the stiffness increases due to the null displacement imposed on the direction $\mathrm{z}$. The inflection region verified at these graphics, around $\phi$ equal to $60^{\circ}$, occurs due to the formulation via $\mathrm{CCA}^{19}$, which predicts smaller stresses for $\phi$ higher than $60^{\circ}$. In this analytical formulation, the equation terms with the highest contribution for the axial stress are multiplied by the co-sin trigonometric function, which average value is obtained for an angle equal to $60^{\circ}$. Finally, in Figure 5b, it can be verified that the maximum and minimum values for the radial displacements, shown by Figure $2 \mathrm{a}$ and $3 \mathrm{a}$. These graphics provide coherent results with the literature information, because the reinforcement volume fraction is increased, and the tube becomes stiffer. For this case, it has the smallest displacement. On the other hand, for larger lamination angle, stiffness in the radial direction reduces, increasing the respective displacement.

\section{Laminated Composite Tube}

In order to improve the previous analytical formulation, the composite tube analyzed in this section consists of several sets with different lamination angles and different materials per set (Figure 6). The material is considered anisotropic in the global coordinate system, i.e., cylindrical coordinates system $(r-\theta-z)$. The thick-walled tube is made of multiple stacked plies sets with fibers aligned in a lamination angle $\phi$ different of zero.

Table 1. Mechanical properties of fibers and polymeric matrix.

\begin{tabular}{|c|c|c|c|c|}
\hline Material & Young's modulus (E) & Bulk modulus (K) & Shear modulus (G) & Poisson's ratio $(v)$ \\
\hline S-Glass fiber, generic ${ }^{21}$ & $86 \mathrm{GPa}$ & $52.80 \mathrm{GPa}^{* *}$ & $35 \mathrm{GPa}$ & 0.220 \\
\hline Graphite fiber (T50) ${ }^{22}$ & $388 \mathrm{GPa}$ & $7.03 \mathrm{GPa}$ & 4.6 GPa* & $0.358 *$ \\
\hline EPON 828 (MDA cured $)^{23}$ & $3.76 \mathrm{GPa}^{*}$ & $5.32 \mathrm{GPa}^{* *}$ & $1.36 \mathrm{GPa}^{*}$ & $0.374 *$ \\
\hline
\end{tabular}

*Average values; **Calculate values. 


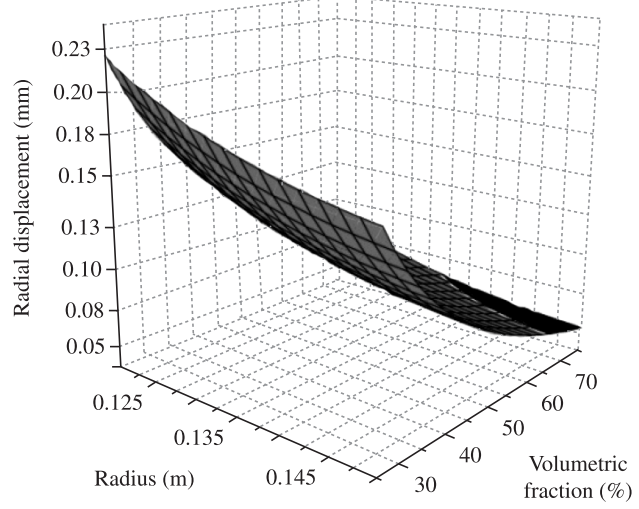

(a)

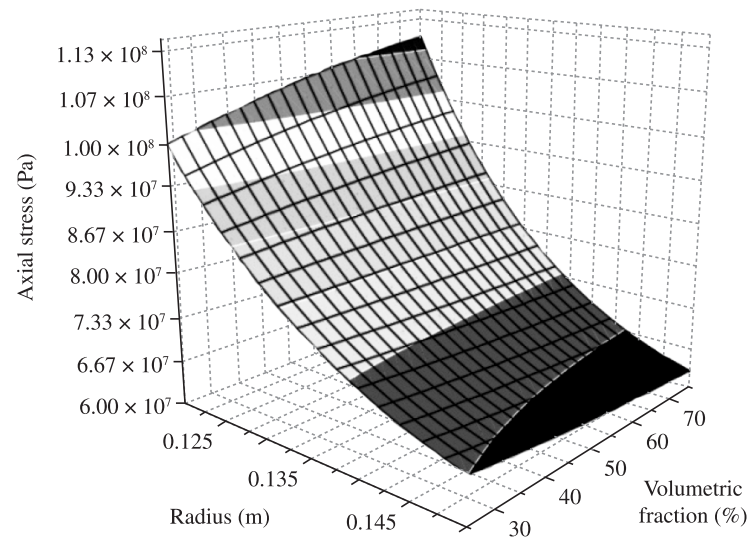

(c)

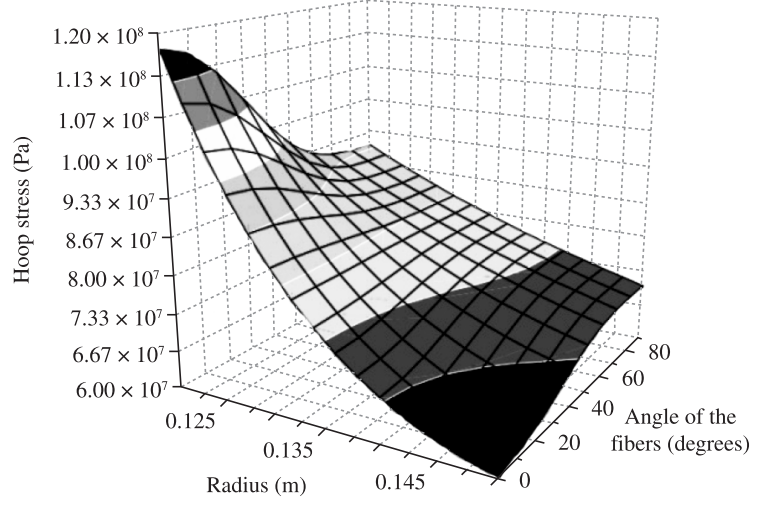

(b)

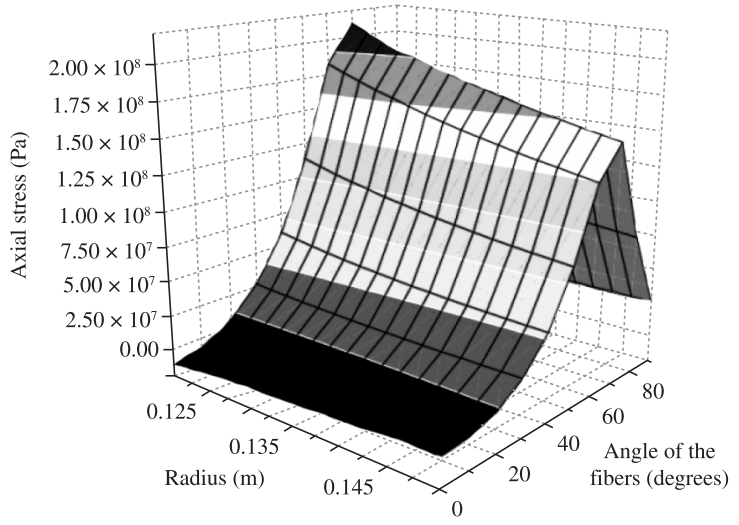

(d)

Figure 2. Stress distribution and radial displacement (graphite fiber reinforcement): a) radial displacement for $\phi=30^{\circ}$, b) hoop stress for $\mathrm{w}=50 \%, \mathrm{c})$ axial stress for $\phi=30^{\circ}$, and d) axial stress for $\mathrm{w}=50 \%$.

For this second analytical formulation, a specific lamination pattern is chosen; so it is possible to calculate the laminated tube with orthotropic properties, using the same approach performed by the first analytical formulation. Thus, the stacking sequence and the directions of the fibers for each ply are taken such as the tube material can be assumed orthotropic.

\subsection{Theoretical formulation-part 2}

Composite laminates with angle-ply layers $\left(0<\phi<90^{\circ}\right)$ and with symmetric stacking sequence were investigated, because this type of configuration is very commonly used for laminated tubes. As observed in Figure 7, the line of symmetry is not at the center of the laminate thickness (Figure 7a), but it is at the center of the tube (Figure 7b). The subscript $\mathrm{s}$ stands for this symmetry. The angles $\pm \mathrm{A}$ and $\pm \mathrm{B}$ are arranged in order to avoid the coupling between normal forces and shear strains. However the coupling between bending and twisting cannot be neglected. It is worth noting that, for a fixed stacking sequence, if the thickness of the plies is reduced and the number of the plies is increased, then this coupling effect can be neglected as much as the plies are thin. Thus, when this analytical formulation is used, laminated tubes with thinner plies show more accurate results. This occurs because the distances between the plies $+\phi$ and $-\phi$ opposed to each other from the center of symmetry tend to the same value, minimizing the bendingtwisting coupling effect.

The calculation of the constitutive matrix of these laminates [Q] depends on the constitutive matrixes of the plies [C] calculated for the plies with negative and positive angles at the angle-ply laminate written in a global system $(\mathrm{r}-\theta-\mathrm{z})$. Using these matrixes in the equilibrium and compatibility equations, it is possible to define the average strains and stresses of this laminate as shown by Equations 23-24. Furthermore, the equivalent orthotropic matrix of the problem is defined by Equation 25, and the respective coefficients by Equations 26-27:

$\bar{\varepsilon}_{i}=\varepsilon_{i}^{k} ; \quad \bar{\sigma}_{i}=\frac{1}{N} \sum_{k=1}^{N} \sigma_{i}^{k} \rightarrow i=1,2,6$

$\bar{\varepsilon}_{i}=\frac{1}{N} \sum_{k=1}^{N} \varepsilon_{i}^{k} ; \quad \bar{\sigma}_{i}=\sigma_{i}^{k} \rightarrow i=3,4,5$ 


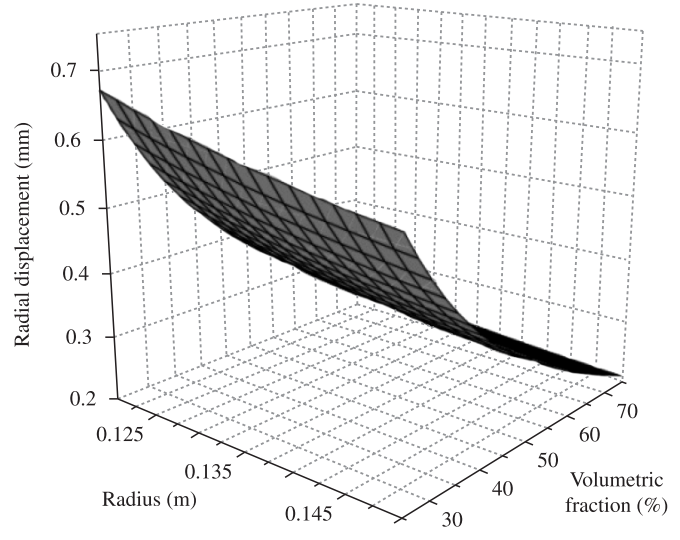

(a)

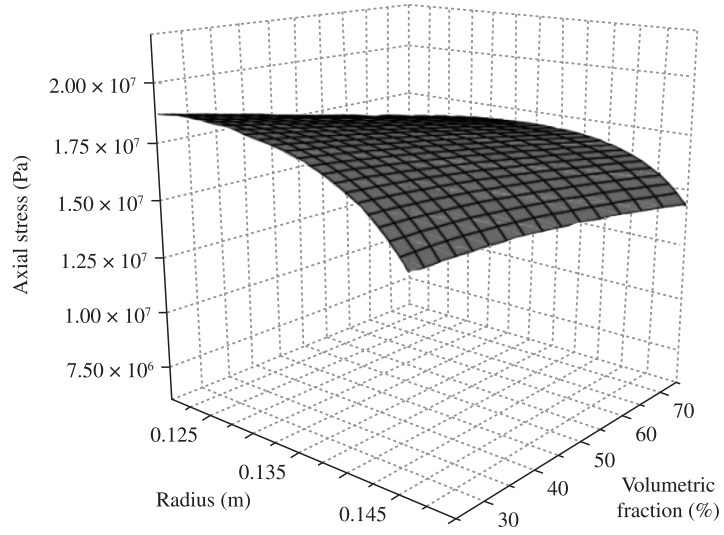

(c)

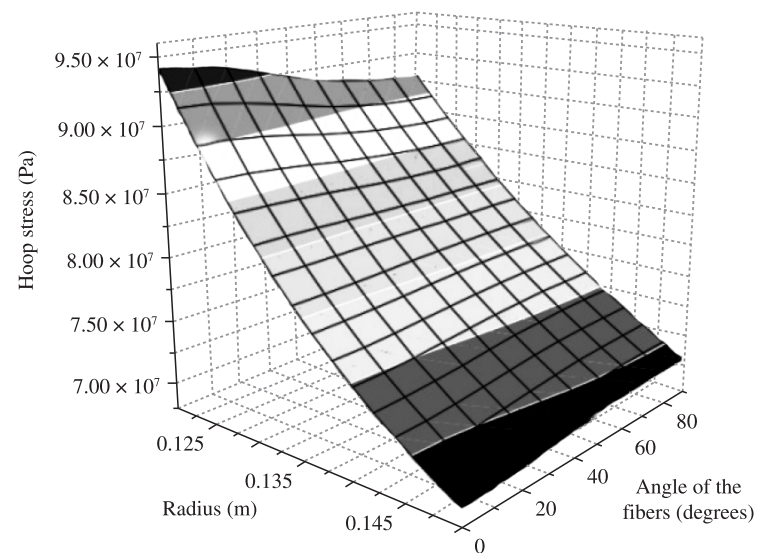

(b)

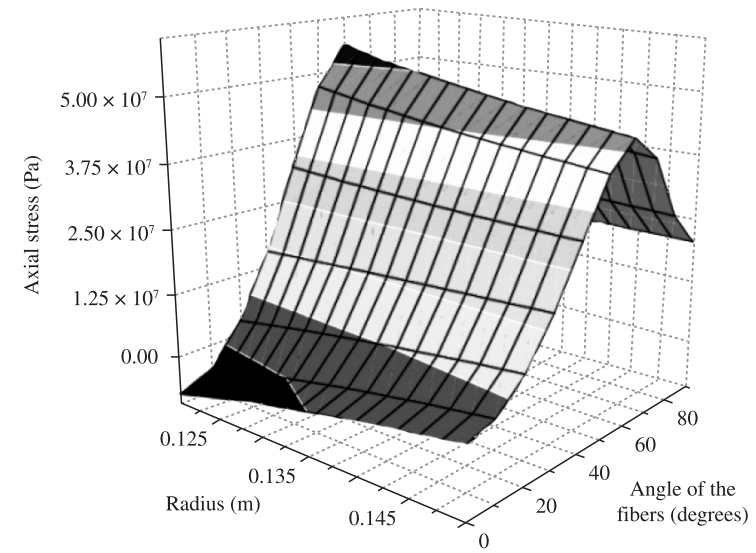

(d)

Figure 3. Stress distribution and radial displacement (glass fiber reinforcement): a) radial displacement for $\phi=30^{\circ}$; b) hoop stress for $\mathrm{w}=50 \%$; c) axial stress for $\phi=30^{\circ} ; \mathrm{d}$ ) axial stress for $\mathrm{w}=50 \%$.

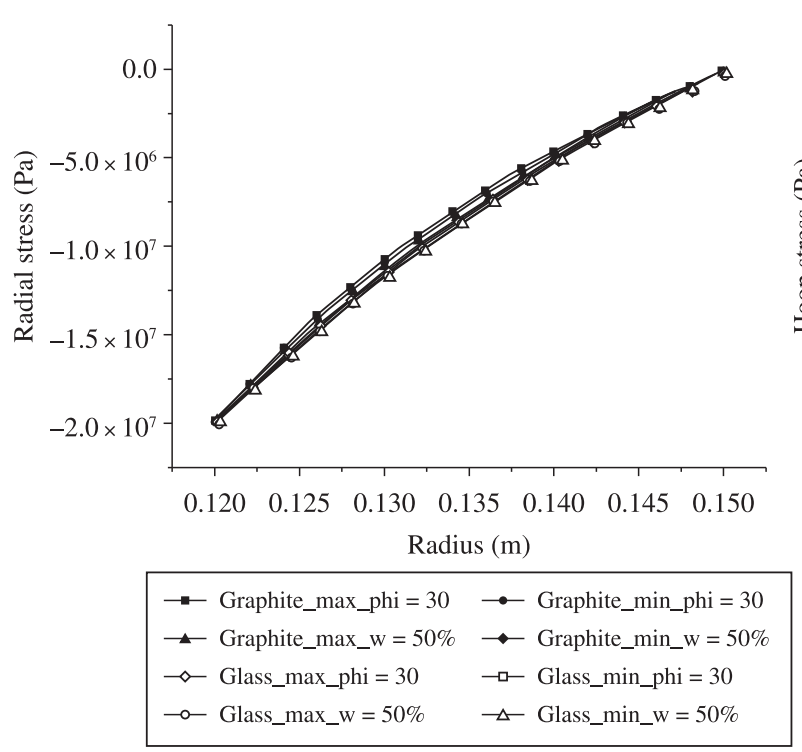

(a)

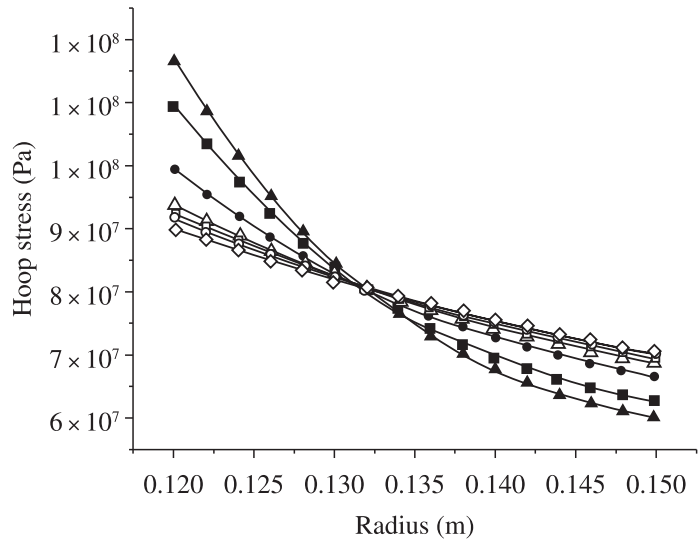

$\begin{array}{ll}\rightarrow \text { Graphite_max_phi }=30 & \rightarrow \text { Graphite_min_phi }=30 \\ \multimap \text { Graphite_max_w }=50 \% & \rightarrow \text { Graphite_min_w }=50 \% \\ \rightarrow-\text { Glass_max_phi }=30 & \multimap \text { Glass_min_phi }=30 \\ - \text { Glass_max_w }=50 \% & \multimap \text { Glass_min_w }=50 \%\end{array}$

(b)

Figure 4. Maximums and minimums values of stress: a) radial stress; b) hoop stress. 


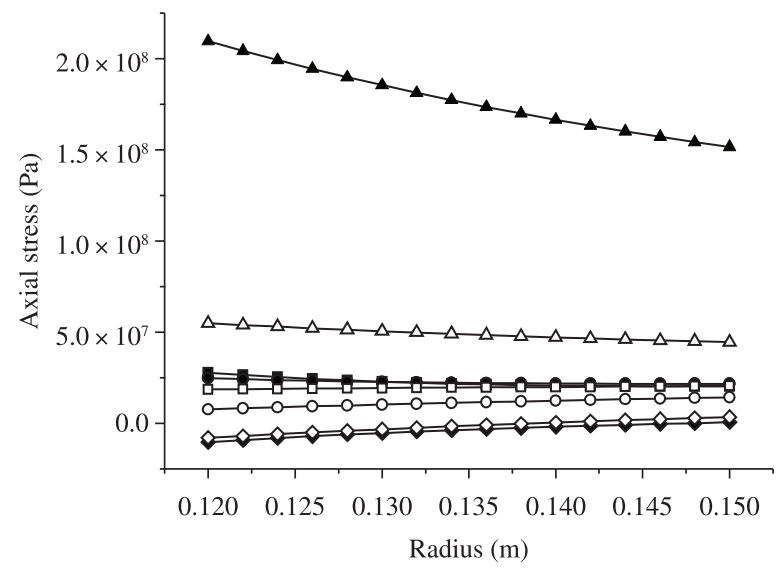

(a)

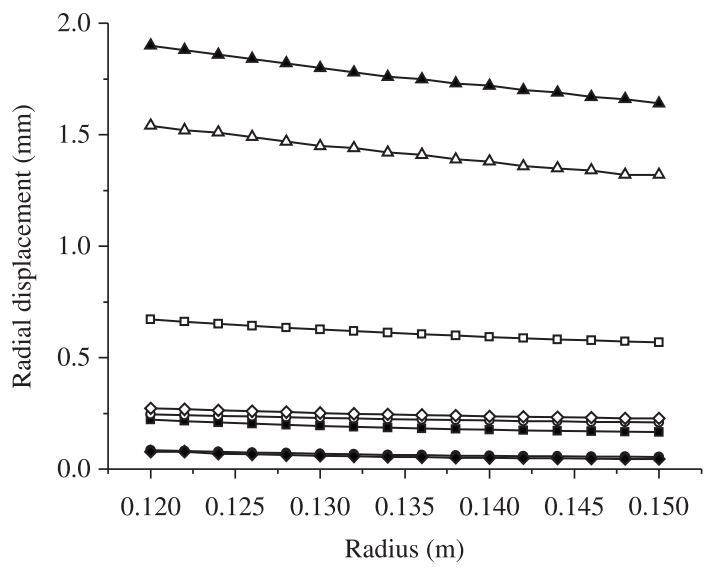

(b)

$$
\begin{array}{ll}
- \text { Graphite_max_phi }=30 & \rightarrow-\text { Glass_max_phi }=30 \\
\rightarrow \text { Graphite_min_phi }=30 & \multimap \text { Glass_min_phi }=30 \\
\multimap \text { Graphite_max_w }=50 \% & -\checkmark \text { Glass_max_w }=50 \% \\
- \text { Graphite_min_w }=50 \% & \multimap \text { Glass_min_w }=50 \%
\end{array}
$$

Figure 5. Maximums and minimums values: a) axial stress; b) radial displacements.

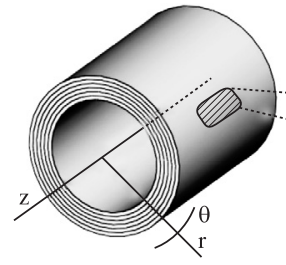

(a)

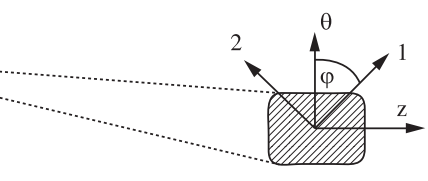

(b)

Figure 6. Thick laminate tube: a) thick walled tube with several plies; b) coordinate systems.

$[Q]=\left[\begin{array}{cccccc}Q_{11} & Q_{12} & Q_{13} & 0 & 0 & 0 \\ Q_{12} & Q_{22} & Q_{23} & 0 & 0 & 0 \\ Q_{13} & Q_{23} & Q_{33} & 0 & 0 & 0 \\ 0 & 0 & 0 & Q_{44} & 0 & 0 \\ 0 & 0 & 0 & 0 & Q_{55} & 0 \\ 0 & 0 & 0 & 0 & 0 & Q_{66}\end{array}\right] \rightarrow$ for $:(\bar{\sigma})=[Q](\bar{\varepsilon})$

$Q_{i j}=\frac{1}{N} \sum_{r=1}^{n} \sum_{k=1}^{N_{S}}{ }^{r} C_{i j}^{k} \rightarrow i j=11,12,13,22,23,33,66$

$$
Q_{44}=\frac{N}{\sum_{r=1}^{n} \sum_{k=1}^{N_{S}} \frac{{ }^{r} C_{55}^{k}}{{ }^{r} C_{44}^{k}{ }^{r} C_{55}^{k}-{ }^{r} C_{45}^{k}{ }^{r} C_{45}^{k}}} ;
$$$$
Q_{55}=\frac{N}{\sum_{r=1}^{n} \sum_{k=1}^{N_{S}} \frac{{ }^{r} C_{44}^{k}}{{ }^{r} C_{44}^{k}{ }^{r} C_{55}^{k}-{ }^{r} C_{45}^{k}{ }^{r} C_{45}^{k}}}
$$

The value of $\mathrm{N}$ is the total number of plies and the value of $n$ is the total number of sets in the laminate; $k$ is a numeric identification of each ply and $\mathrm{r}$ indicates the set,

which has a material, a lamination angle and a number of layers $\mathrm{N}_{\mathrm{S}}$. In this second analytical formulation, it is very strategic to use equivalent properties, because consistent values are obtained for composite tubes manufactured by filament winding. Applying the same loads and boundary conditions uses at the first analytical formulation, the global stresses (radial, hoop and axial) and the radial displacement are calculated by:

$$
\begin{aligned}
& \sigma_{r}(r)=\left[\frac{P_{e}\left(r_{i} / r_{e}\right)^{-(1+\alpha)}-P_{i}}{r_{i}^{\alpha-1}-r_{e}^{2 \alpha} r_{i}^{-(1+\alpha)}}\right] r^{\alpha-1} \\
& -\left[\frac{P_{e}}{r_{e}^{-(1+\alpha)}}+\frac{\left(P_{e}\left(r_{i} / r_{e}\right)^{-(1+\alpha)}-P_{i}\right)}{\left(r_{i}^{\alpha-1} / r_{e}^{2 \alpha}\right)-r_{i}^{-(\alpha+1)}}\right] r^{-(\alpha+1)} \\
& \sigma_{\theta}(r)=\left[\frac{P_{e}\left(r_{i} / r_{e}\right)^{-(1+\alpha)}-P_{i}}{r_{i}^{\alpha-1}-r_{e}^{2 \alpha} r_{i}^{-(1+\alpha)}}\right] \frac{\left(Q_{11}+\alpha Q_{13}\right)}{\left(Q_{13}+\alpha Q_{33}\right)} r^{\alpha-1} \\
& -\left[\frac{P_{e}}{r_{e}^{-(1+\alpha)}}+\frac{\left(P_{e}\left(r_{i} / r_{e}\right)^{-(1+\alpha)}-P_{i}\right)}{\left(r_{i}^{\alpha-1} / r_{e}^{2 \alpha}\right)-r_{i}^{-(\alpha+1)}}\right] \frac{\left(Q_{11}-\alpha Q_{13}\right)}{\left(Q_{13}-\alpha Q_{33}\right)} r^{-(\alpha+1)} \\
& \sigma_{z}(r)=\left[\frac{P_{e}\left(r_{i} / r_{e}\right)^{-(1+\alpha)}-P_{i}}{r_{i}^{\alpha-1}-r_{e}^{2 \alpha} r_{i}^{-(1+\alpha)}}\right] \frac{\left(Q_{12}+\alpha Q_{23}\right)}{\left(Q_{13}+\alpha Q_{33}\right)} r^{\alpha-1} \\
& -\left[\frac{P_{e}}{r_{e}^{-(1+\alpha)}}+\frac{\left(P_{e}\left(r_{i} / r_{e}\right)^{-(1+\alpha)}-P_{i}\right)}{\left(r_{i}^{\alpha-1} / r_{e}^{2 \alpha}\right)-r_{i}^{-(\alpha+1)}}\right] \frac{\left(Q_{12}-\alpha Q_{23}\right)}{\left(Q_{13}-\alpha Q_{33}\right)} r^{-(\alpha+1)} \\
& u(r)=\frac{1}{\left(Q_{13}+\alpha Q_{33}\right)}\left[\frac{P_{e}\left(r_{i} / r_{e}\right)^{-(1+\alpha)}-P_{i}}{r_{i}^{\alpha-1}-r_{e}^{2 \alpha} r_{i}^{-(1+\alpha)}}\right] r^{\alpha} \\
& -\frac{1}{\left(Q_{13}-\alpha Q_{33}\right)}\left[\frac{P_{e}}{r_{e}^{-(1+\alpha)}}+\frac{\left(P_{e}\left(r_{i} / r_{e}\right)^{-(1+\alpha)}-P_{i}\right)}{\left(r_{i}^{\alpha-1} / r_{e}^{2 \alpha}\right)-r_{i}^{-(\alpha+1)}}\right] r^{-\alpha}
\end{aligned}
$$




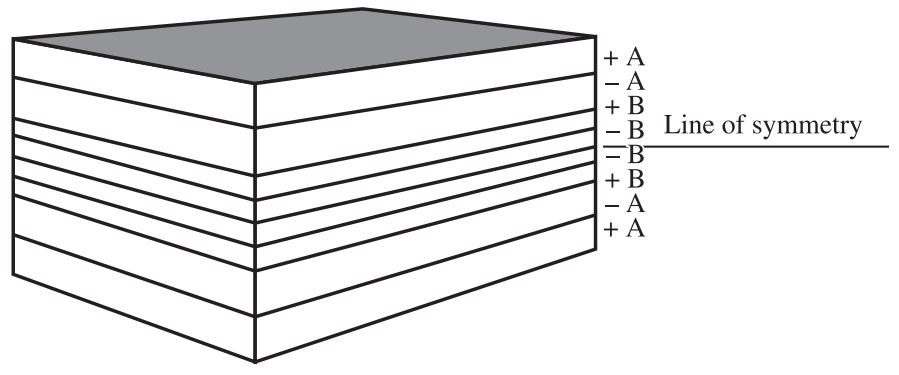

(a)

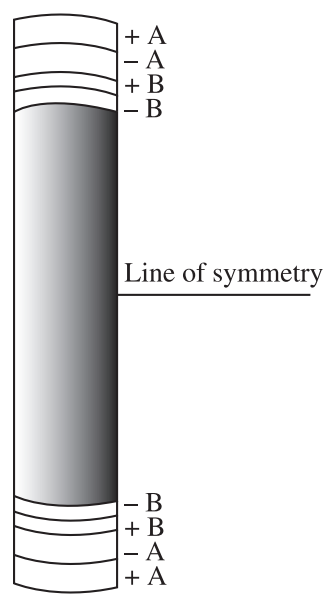

(b)

Figure 7. Lamination symmetry: a) angle-ply and symmetric laminate $[+\mathrm{A} /-\mathrm{A} /+\mathrm{B} /-\mathrm{B}]_{\mathrm{s}}$; b) front section of the laminate tube with an equivalent symmetry.

For $: \alpha=\left(Q_{11} / Q_{33}\right)^{1 / 2}$

The thick-walled tube made of composite material has a constitutive matrix, which varies with elastic properties and with the lamination angle. The tube herein studied can be analyzed as several co-axial orthotropic tubes with specific elastic properties each one $\left(\mathrm{E}_{11}, \mathrm{E}_{22}, \mathrm{E}_{33}, \mathrm{G}_{31}, \mathrm{G}_{23}, \mathrm{G}_{12}, \mathrm{v}_{31}\right.$, $v_{23}$ and $v_{12}$ ). There are some relations between these elastic properties where slight variation of a property value implies in an abrupt modification of the others. Thus, these variations must follow some restrictions, as shown by Equations 33-36, in order to keep the orthotropic symmetry and guarantee the hypothesis used by the proposed analytical formulation.

$E_{11}, E_{22}, E_{33}, G_{31}, G_{23}, G_{12}>0$

$\left|v_{12}\right|<\sqrt{E_{11} / E_{22}} ;\left|v_{13}\right|<\sqrt{E_{11} / E_{33}} ;\left|v_{23}\right|<\sqrt{E_{22} / E_{33}}$

$\left|v_{21}\right|<\sqrt{E_{22} / E_{11}} ;\left|v_{31}\right|<\sqrt{E_{33} / E_{11}} ;\left|v_{32}\right|<\sqrt{E_{33} / E_{22}}$

$v_{31} v_{12} v_{23}<\left\{\begin{array}{l}{\left[1-v_{31}^{2}\left(E_{11} / E_{33}\right)\right.} \\ \left.-v_{12}^{2}\left(E_{22} / E_{11}\right)-v_{23}^{2}\left(E_{33} / E_{22}\right)\right] / 2\end{array}\right\}<0,5$

It is important to highlight that to predict the laminate behavior, using an equivalent orthotropic material, the constitutive matrix in Equation 25 should be written in terms of the equivalent properties. Therefore, it is possible to check if the analysis carried out is physically supported, evaluating the restrictions described for each stacking sequence. To apply the restrictions, it is necessary to obtain the equivalent properties of the tube as a function of the average coefficients of the laminate (calculated by Equatiuons 26-27). Using the average constitutive matrix of the laminated tube [Q], the properties are calculated by following equations:

$$
\begin{aligned}
& v_{31}=-\frac{Q_{32} Q_{12}-Q_{31} Q_{22}}{Q_{11} Q_{22}-Q_{12}^{2}} ; v_{23}=-\frac{Q_{31} Q_{12}-Q_{32} Q_{11}}{Q_{11} Q_{33}-Q_{31}^{2}} ; \\
& v_{12}=-\frac{Q_{31} Q_{32}-Q_{12} Q_{33}}{Q_{33} Q_{22}-Q_{32}^{2}} ; \\
& E_{33}=\frac{\lambda}{Q_{11} Q_{22}-Q_{12}^{2}} ; \quad E_{11}=\frac{\lambda}{Q_{33} Q_{22}-Q_{32}^{2}} ; \\
& E_{22}=\frac{\lambda}{Q_{11} Q_{33}-Q_{31}^{2}} ;
\end{aligned}
$$

for $: \lambda=Q_{11} Q_{22} Q_{33}-2 Q_{31} Q_{12} Q_{32}$

$-Q_{31}^{2} Q_{22}-Q_{12}^{2} Q_{33}-Q_{32}^{2} Q_{11}$

The Equations 37-39 combined to the Equations 33-36 define the possible variations for the elastic properties. Therefore, each modification at $\mathrm{E}_{\mathrm{ij}}$, for instance, can represent a combination of changes for the materials used in the manufacturing of the laminate. Thus, not only the Young's moduli can be affected but also all the remaining equivalent properties. Then, within a limit for the variations of a specific property, one must re-calculate the other ones via Equations 37-39 and verify whether the results violate the restrictions or not, using Equations 33-36. If any of these restrictions is violated, the proposed analytical formulation becomes unreliable, because the equivalent elastic properties cannot correspond to a real orthotropic structure. Since the restrictions have been verified, the theoretical model can be applied to calculate the local stresses in each ply k of the composite tube. To determine these stresses, it is necessary to obtain the strains in each ply in the global system of coordinates ( $r-\theta-z)$ using Equations 23 and 24. Considering the pressures applied on the tube, the tensor of the average strains is given by:

$(\bar{\varepsilon})=\left(\begin{array}{ccc}\bar{\varepsilon}_{\theta \theta} & 0 & 0 \\ 0 & 0 & 0 \\ 0 & 0 & \bar{\varepsilon}_{r r}\end{array}\right)$ 
Applying Equations 23 and 24 for the strains of the plies in global coordinate system, it can be verified that these results represent the average local strains, also. Then, these strains in the local system of coordinates (1-2-3) of each ply $\mathrm{k}$ are given by:

$$
\begin{aligned}
& {\left[\varepsilon_{11}\right]_{k}=\left[(\cos \phi)^{2}\right]_{k} \bar{\varepsilon}_{\theta \theta}(r) ; \quad\left[\varepsilon_{22}\right]_{k}=\left[(\sin \phi)^{2}\right]_{k} \bar{\varepsilon}_{\theta \theta}(r) ;} \\
& {\left[\varepsilon_{33}\right]_{k}=\bar{\varepsilon}_{r r}(r) ; \quad\left[\tau_{12}\right]_{k}=[\sin \phi \cos \phi]_{k} \bar{\varepsilon}_{\theta \theta}(r)}
\end{aligned}
$$

Finally, the local stresses are calculated for the local constitutive matrix of each ply $[\mathrm{C}]^{\mathrm{k}}$ with orthotropic features. The local strains in each $\mathrm{k}$ ply are calculated by the Equations 42-46 in functions of the radius $r$ given by Equation 41 and considering the Equations 3, 6 and 23, 24.

$$
\begin{aligned}
& {\left[\sigma_{11}(r)\right]_{k}=\left(\frac{\left[C_{11}^{*}(\cos \phi)^{2}+C_{12}^{*}(\sin \phi)^{2}+\alpha C_{13}^{*}\right] k}{Q_{13}+\alpha Q_{33}}\right) H\left[r^{\alpha-1}\right]_{k}} \\
& -\left(\frac{\left[C_{11}^{*}(\cos \phi)^{2}+C_{12}^{*}(\sin \phi)^{2}-\alpha C_{13}^{*}\right] k}{Q_{13}-\alpha Q_{33}}\right) F\left[r^{-(\alpha+1)}\right]_{k} \\
& {\left[\sigma_{22}(r)\right]_{k}=\left(\frac{\left[C_{12}^{*}(\cos \phi)^{2}+C_{22}^{*}(\sin \phi)^{2}+\alpha C_{23}^{*}\right] k}{Q_{13}+\alpha Q_{33}}\right) H\left[r^{\alpha-1}\right]_{k}} \\
& -\left(\frac{\left[C_{12}^{*}(\cos \phi)^{2}+C_{22}^{*}(\sin \phi)^{2}-\alpha C_{23}^{*}\right] k}{Q_{13}-\alpha Q_{33}}\right) F\left[r^{-(\alpha+1)}\right]_{k} \\
& {\left[\sigma_{33}(r)\right]_{k}=\left(\frac{\left[C_{13}^{*}(\cos \phi)^{2}+C_{23}^{*}(\sin \phi)^{2}+\alpha C_{33}^{*}\right] k}{Q_{13}+\alpha Q_{33}}\right) H\left[r^{\alpha-1}\right]_{k}} \\
& -\left(\frac{\left[C_{13}^{*}(\cos \phi)^{2}+C_{23}^{*}(\sin \phi)^{2}-\alpha C_{33}^{*}\right] k}{Q_{13}-\alpha Q_{33}}\right) F\left[r^{-(\alpha+1)}\right]_{k} \\
& {\left[\tau_{12}(r)\right]_{k}=\left[\sin (2 \phi) C_{66}^{*}\right]_{k}\left\{\begin{array}{l}
\left(\frac{1}{Q_{13}+\alpha Q_{33}}\right) H\left[r^{\alpha-1}\right]_{k} \\
-\left(\frac{1}{Q_{13}-\alpha Q_{33}}\right) F\left[r^{-(\alpha+1)}\right]_{k}
\end{array}\right\}}
\end{aligned}
$$

$F=\left[\frac{P_{e}}{r_{e}^{-(1+\alpha)}}+\frac{\left(P_{e}\left(r_{i} / r_{e}\right)^{-(1+\alpha)}-P_{i}\right)}{\left(r_{i}^{\alpha-1} / r_{e}^{2 \alpha}\right)-r_{i}^{-(\alpha+1)}}\right]$;

It is important to mention that the local stresses are functions of the equivalent properties of the laminate $Q_{i j}$ as well as the properties of each ply $\mathrm{C}_{\mathrm{ij}}{ }^{*}$. In the terms $\left[\mathrm{r}^{\alpha-1}\right]$ ${ }_{\mathrm{k}}$ and $\left[\mathrm{r}^{-(\alpha+1)}\right]_{\mathrm{k}}$, the subscript $\mathrm{k}$ restricts the generic solutions of the laminate for the plies, because the values of radius $r$ are chosen according to the relative positions of the plies in the laminate and respective thicknesses.

\subsection{Results for laminated tube}

In order to verify the accuracy of the presented analytical formulation, a numerical model was developed using a finite element software, Ansys ${ }^{\mathrm{TM}}$. The results for stresses calculated by analytical and numerical approaches were compared. As discussed in the first analytical formulation, the second one was implemented via Matlab code as an engineering computational tool, also.

To carry out a more trustful comparison, the CCA (Composite Cylinder Assemblage) developed by Hashin ${ }^{18}$ was not used to obtain the elastic properties for a specific material even though the computational tool herein developed allows this possibility. Thus, a commercial material (unidirectional prepreg manufactured by Hexcel ${ }^{\mathrm{TM}}$ ), which the elastic properties and strength values were evaluated by Tita et al. ${ }^{17}$ (Table 2), was selected. Therefore, it was studied the influence of the lamination angle, as well as the stacking sequence on the mechanical behavior of the composite tubes.

The computational tool was used to calculate the stress distribution in the tube with stacking sequence equal to $\left[45^{\circ}{ }_{10} /-45^{\circ}{ }_{10} / 30^{\circ}{ }_{10} /-30^{\circ}{ }_{10}\right]_{\mathrm{s}}$. The first 20 plies have $0.0005 \mathrm{~m}$ of thickness whereas the last 20 plies have $0.001 \mathrm{~m}$ of thickness. The tube has an internal radio equal to $0.12 \mathrm{~m}$ and an external one equal to $0.15 \mathrm{~m}$. The internal pressure applied is equal to $20 \mathrm{MPa}$ and the external pressure is equal to $0.1 \mathrm{MPa}$.

The numerical model has 19200 layered elements (SOLID191 - Ansys ${ }^{\text {TM }}$ finite element). Each layered element has 10 plies defined according to the stacking sequence mentioned earlier (Figure 8a). The composite tube was modeled with one meter of length. The boundary conditions were applied in order to represent a section of a long tube analyzed by the analytical formulation. The tube was clamped at both ends (Figure $8 \mathrm{~b}$ ). The results were taken away from the ends of the tube in order to avoid that border effects influence the numerical results.

The comparison between results from the computational tool and the finite element analyses showed coherent results (Table 3$)$. The largest difference $(37.1 \%)$ is presented by the axial stress component for only one ply. However, for the other plies and stress components, the maximum difference

\begin{tabular}{|c|c|c|c|c|c|c|}
\hline \multicolumn{2}{|c|}{ Young's modulus } & \multicolumn{2}{|c|}{ Shear modulus } & \multicolumn{2}{|c|}{ Poisson's ratio } & \multirow{2}{*}{$\begin{array}{c}\text { Density } \\
\rho\end{array}$} \\
\hline $\mathbf{E}_{11}$ & $\mathbf{E}_{22}=\mathbf{E}_{33}$ & $G_{12}=G_{13}$ & $\mathbf{G}_{23}$ & $v_{12}=v_{13}$ & $v_{23}$ & \\
\hline $127 \mathrm{GPa}$ & $10 \mathrm{GPa}$ & $5.4 \mathrm{GPa}$ & $3.05 \mathrm{GPa}$ & 0.34 & 0.306 & $1580 \mathrm{~kg} \cdot \mathrm{m}^{-3}$ \\
\hline
\end{tabular}
is equal to $12.4 \%$ in the hoop stress. These differences are mainly due to the simplification of the analytical formulation, which uses equivalent orthotropic properties and shows in Equation 40 that some strain components are neglected. Unlike the finite element analyses with $3 \mathrm{D}$ elements (SOLID 191) consider all components of the strain tensor and does not use equivalent orthotropic properties.

Table 2. Mechanical properties for the M10 prepreg material (Hexcel $\left.{ }^{\mathrm{TM}}\right)$. 


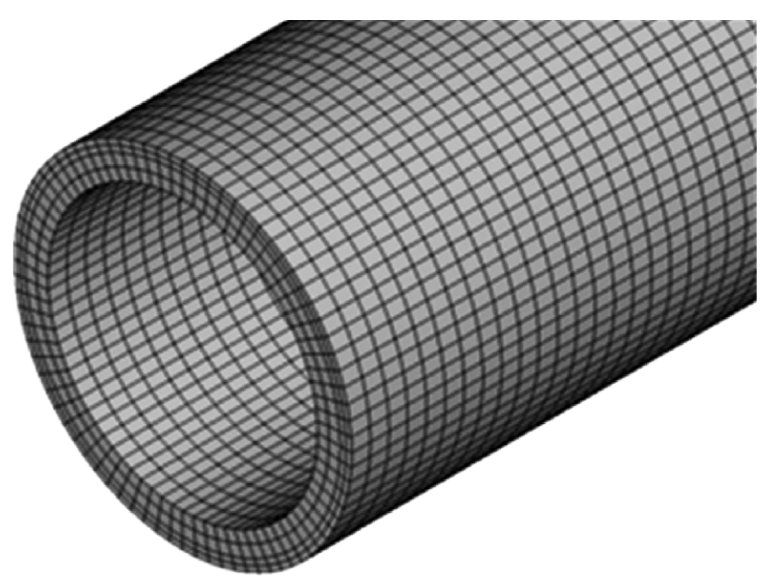

(a)

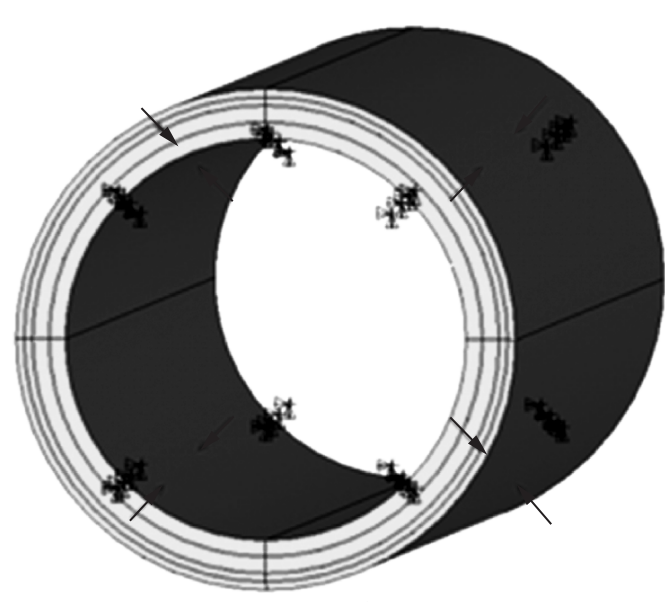

(b)

Figure 8. Finite element model: a) finite element mesh; b) boundary conditions and pressure loadings.

Table 3. Comparison between analytical and numerical results.

\begin{tabular}{ccccccccc}
\hline Set & $\mathbf{1}$ & $\mathbf{1}$ & $\mathbf{2}$ & $\mathbf{2}$ & $\mathbf{3}$ & $\mathbf{3}$ & $\mathbf{4}$ & $\mathbf{4}$ \\
$\mathbf{P l y}$ & $\mathbf{1}$ & $\mathbf{1 0}$ & $\mathbf{1}$ & $\mathbf{1 0}$ & $\mathbf{1}$ & $\mathbf{1 0}$ & $\mathbf{1}$ & $\mathbf{1 0}$ \\
Radio $[\mathbf{m}]$ & $\mathbf{0 . 1 2}$ & $\mathbf{0 . 1 3}$ & $\mathbf{0 . 1 3}$ & $\mathbf{0 . 1 4}$ & $\mathbf{0 . 1 4}$ & $\mathbf{0 . 1 4 5}$ & $\mathbf{0 . 1 4 5}$ & $\mathbf{0 . 1 5}$ \\
\hline$\sigma_{\theta}(*)[\mathbf{P a}]$ & $1.42 \mathrm{E}+08$ & $1.21 \mathrm{E}+08$ & $1.20 \mathrm{E}+08$ & $1.07 \mathrm{E}+08$ & $7.25 \mathrm{E}+07$ & $6.95 \mathrm{E}+07$ & $6.92 \mathrm{E}+07$ & $6.65 \mathrm{E}+07$ \\
$\sigma_{\theta}(* *)[\mathbf{P a}]$ & $1.61 \mathrm{E}+08$ & $1.37 \mathrm{E}+08$ & $1.37 \mathrm{E}+08$ & $1.21 \mathrm{E}+08$ & $8.11 \mathrm{E}+07$ & $7.75 \mathrm{E}+07$ & $7.75 \mathrm{E}+07$ & $7.47 \mathrm{E}+07$ \\
$\Delta(\boldsymbol{\%})$ & 11.8 & 11.7 & 12.4 & 11.6 & 10.6 & 10.3 & 10.7 & 11.0 \\
$\sigma_{\mathbf{z}}(*)[\mathbf{P a}]$ & $1.69 \mathrm{E}+06$ & $3.48 \mathrm{E}+06$ & $3.44 \mathrm{E}+06$ & $4.81 \mathrm{E}+06$ & $6.70 \mathrm{E}+06$ & $6.70 \mathrm{E}+06$ & $6.80 \mathrm{E}+06$ & $6.90 \mathrm{E}+06$ \\
$\sigma_{\mathbf{z}}(* *)[\mathbf{P a}]$ & $2.69 \mathrm{E}+06$ & $3.87 \mathrm{E}+06$ & $3.87 \mathrm{E}+06$ & $4.90 \mathrm{E}+06$ & $6.86 \mathrm{E}+06$ & $7.23 \mathrm{E}+06$ & $7.23 \mathrm{E}+06$ & $7.59 \mathrm{E}+06$ \\
$\Delta(\%)$ & 37.1 & 10.1 & 11.1 & 1.8 & 2.3 & 7.3 & 5.9 & 9.1 \\
$\tau_{\theta-\mathbf{r}}(*)[\mathbf{P a}]$ & $-7.27 \mathrm{E}+06$ & $-6.16 \mathrm{E}+06$ & $6.17 \mathrm{E}+06$ & $5.35 \mathrm{E}+06$ & $-6.20 \mathrm{E}+06$ & $-5.80 \mathrm{E}+06$ & $5.80 \mathrm{E}+06$ & $5.50 \mathrm{E}+06$ \\
$\tau_{\theta-\mathbf{r}}(* *)[\mathbf{P a}]$ & $-8.21 \mathrm{E}+06$ & $-6.85 \mathrm{E}+06$ & $6.85 \mathrm{E}+06$ & $5.93 \mathrm{E}+06$ & $-6.69 \mathrm{E}+06$ & $-6.46 \mathrm{E}+06$ & $6.46 \mathrm{E}+06$ & $6.14 \mathrm{E}+06$ \\
$\Delta(\boldsymbol{\%})$ & 11.4 & 10.1 & 9.9 & 9.8 & 7.3 & 10.2 & 10.2 & 10.4 \\
\hline
\end{tabular}

*ANSYS Results; **computational tool; N/A: not available; $\Delta=\{1-[(*) /(* *)]\} \times 100$.

Table 4. Failure analyses using the computational tool.

\begin{tabular}{ccccc}
\hline Ply & Set & Fail & Criterion & Failure mode \\
\hline 1 & 1 & Yes & Hoffman & N/A \\
1 & 1 & Yes & Hashin & C-M, T-M \\
1 & 1 & Yes & ${\text { Tita et al. }{ }^{17}}$ & C-M, T-M \\
1 & 1 & Yes & Max. Stress & C-M $\left(^{*}\right)$ \\
2 & 1 & Yes & Hoffman & N/A \\
2 & 1 & Yes & Hashin & C-M, T-M \\
2 & 1 & Yes & Tita et al. ${ }^{17}$ & T-M \\
2 & 1 & Yes & Max. Stress & C-M $(*)$ \\
10 & 4 & Yes & Hoffman & N/A \\
10 & 4 & No & Hashin & - \\
10 & 4 & No & Tita et al. ${ }^{17}$ & - \\
10 & 4 & No & Max. Stress & - \\
\hline
\end{tabular}

N/A: not available; C: compression; T: tension; M: matrix; $(*)$ failure in direction 3 (through the tube thickness).

Although, the axial stress component contributes to the failure process of the composite tube, the highest absolute stress values are calculated for hoop stress. Thus, the largest difference (37.1\%) presented by the axial stress component will have a very low influence in the failure analyses.

\subsection{Failure analyses of laminated tube}

Four different failure criteria were implemented in the computational tool in order to perform failure analyses for composite tubes, identifying the damaged plies and the failure modes. Thus, three out of the four failure criteria are well known (Maximum stress, Hashin and Hoffman ${ }^{18}$ ) and a new one proposed by Tita et al. ${ }^{17}$, which was never used to predict failure mechanisms for composite tubes. After the implementation, it was carried out the stress and failure analyses for the same laminated tube shown at section 3.2, but for this case, it was applied an internal pressure equal to $100 \mathrm{MPa}$.

Table 4 shows coherent results and physically consistent for all failure criteria implemented. As observed, there is a failure close to the inner radio of composite tube. Furthermore, it is verified that the failure mode occurs in the polymeric matrix under tension and/or compression loading.

\section{Conclusions}

In the first part of the paper, the mechanical behavior of a thick composite tube with a single lamination direction was analyzed using an analytical formulation, which was implemented as an engineering computational tool via Matlab. The results obtained by the theoretical model 
are physically consistent and coherent with the literature information. Therefore, the computational tool is a good alternative to predict the mechanical behavior of general thick composite tube with a single lamination direction, aiding engineers during the conceptual and preliminary design. Mechanical behavior of composite structural repairs with one single orientation for cylindrical structures can be predicted using the computational tool, also.

In the second part of the paper, mechanical behavior of a thick laminated tube can be predicted by another analytical formulation, which was implemented in the computational tool, also. After to compare the results obtained by the analytical formulation to finite element analyses, it can be concluded that the computational tool is a good alternative to predict the stress distribution in thick laminated tube. Moreover, the engineering computational tool can perform failure analysis, using different types of failure criteria, which identifies the damaged ply and the mode of failure.

\section{References}

1. Lekhnitskii SG. Anisotropic plates. New York: Gordon and Breach, Science Publishers; 1968. 20p.

2. Lekhnitskii SG. Theory of elasticity of an anisotropic body. Moscow: Mir; 1981.

3. Durban D. Finite Straining of pressurized compressible elasto-plastic tubes. International Journal of Engineering Science. 1988; 26(9):939-950. http://dx.doi.org/10.1016/00207225(88)90023-7

4. Durban D and Kubi M. Large strain analysis for plasticorthotropic tubes. International Journal of Solids and Structures. 1989; 26(4):483-495. http://dx.doi.org/10.1016/00207683(90)90070-C

5. Wüthrich C. Thick-walled composite tubes under mechanical and hydrothermal loading. Composites. 1992; 23(6):407-413. http://dx.doi.org/10.1016/0010-4361(92)90003-D

6. Sayir M B and Motovalli M. Fiber-reinforced laminated composite tubes with free ends under uniform internal pressure. Journal of the Mechanics and Physics of Solids. 1995; 43(11):1691-1725. http://dx.doi.org/10.1016/00225096(95)00055-N

7. Salzar RS. Functionally graded metal matrix composite tubes. Composites Engineering. 1995; 5(7):891-900. http://dx.doi. org/10.1016/0961-9526(95)00023-G

8. Tarn JQ and Wang YM. Laminated composites tubes under extension, torsion, bending, shearing, and pressuring: a state space approach. International Journal of Solids and Structures. 2000; 38:9053-9075. http://dx.doi.org/10.1016/ S0020-7683(01)00170-6

9. Gning PB, Tarfaoui M, Collombet F, Riou L and Davies P. Damage development in thick composite tubes under impact loading and influence on implosion pressure: experimental observations. Composites: Part B. 2005; 36:306-318. http://dx.doi.org/10.1016/j.compositesb.2004.11.004

10. Onder A, Sayman O, Dogan T and Tarakcioglu N. Burst failure load of composite pressure vessels. Composite Structures. 2009; 89:159-166. http://dx.doi.org/10.1016/j. compstruct.2008.06.021

11. Silvestre N. Non-classical effects in FRP composite tubes. Composites Part B: Engineering. 2009; 40(8):681-697. http://dx.doi.org/10.1016/j.compositesb.2009.07.001
Therefore, the theoretical models implemented as a computational tool allows that the user perform very quickly preliminary analyses of stress distribution and failure mechanisms for pressurized laminated tubes and cylindrical geometries with single lamination direction (like composite structural repairs). In these preliminary analyses, the user can select the composite material (fiber and matrix), the reinforcement volume fraction, the lamination angle and the stacking sequence most adequate for the project in order to improve the mechanical behavior of a composite structure in service.

\section{Acknowledgement}

The authors would like to thank the Sao Paulo Research Foundation (FAPESP - process number: 2009/00544-5) for the financial support. The authors would also like to thank National Council for Research and Development (CNPq).

12. Ansari R, Alisafaei $\mathrm{F}$ and Ghaedi P. Dynamic analysis of multi-layered filament-wound composite pipes subjected to cyclic internal pressure and cyclic temperature. Composite Structures. 2010; 92(5):1100-1109. http://dx.doi.org/10.1016/j. compstruct.2009.09.058

13. Bakaiyan H, Hosseini $\mathrm{H}$ and Ameri E. Analysis of multilayered filament-wound composite pipes under combined internal pressure and thermomechanical loading with thermal variations. Composite Structures. 2009; 88(4):532-541. http://dx.doi.org/10.1016/j.compstruct.2008.05.017

14. Alexander $\mathrm{C}$ and Ochoa OO. Extending onshore pipeline repair to offshore steel risers with carbon-fiber reinforced composites. Composite Structures. 2010; 92(2):499-507. http://dx.doi. org/10.1016/j.compstruct.2009.08.034

15. Shadmehri F, Derisi B and Hoa SV. On bending stiffness of composite tubes. Composite Structures. 2011; 93(9):2173-2179. http://dx.doi.org/10.1016/j.compstruct.2011.03.002

16. Piekarczyk J, Piekarczyk W and Blazewicz S. Compression strength of concrete cylinders reinforced with carbon fiber laminate. Construction and Building Materials. 2011; 25:2365-2369. http://dx.doi.org/10.1016/j. conbuildmat.2010.11.035

17. Tita V, Carvalho J and Vandepitte D. Failure analysis of low velocity impact on thin composite laminates: experimental and numerical approaches. Composite Structures. 2008; 83:413-428. http://dx.doi.org/10.1016/j.compstruct.2007.06.003

18. Mendonça PTR. Materiais compostos e estruturas sanduíche: projeto e análise. Barueri: Manole; 2005.

19. Christensen RM. Mechanics of composite materials. New York: John Wiley \& Sons; 1979.

20. Hashin Z. Analysis of Composite Materials: A Survey. Journal of Applied Mechanics. 1983; 50:481-505. http://dx.doi. org/10.1115/1.3167081

21. Matweb. S-Glass Fiber, Generic. Available from: <http://www. matweb.com>. Access in: 2009.

22. American Society for Metals International. ASM Handbook. The Materials International Society, American Society for Metals - ASM; 2001. v. 21: Composites. 202 p.

23. Edwin MO, Donald F A. An investigation of the isotropy of epoxy polymers. Journal of Materials Research. 1992; 7(12):3352-3358. http://dx.doi.org/10.1557/JMR.1992.3352 